\title{
Raw Material Consumption Controls on Environment Impacts of Sofa Production: A Case Study Based on Ecological Footprint
}

\section{Jianquan', YUAN Yue ${ }^{2}$, LUO Shuzheng ${ }^{3 \dagger}$}

1. Research Institute of Forestry Policy and Information, Chinese Academy of Forestry, Beijing 100091, China;

2. Operation Centre, Chongming Dongtan Nature Reserve of Shanghai City, Shanghai 202162, China;

3. Department of Biological Sciences, Xinzhou Teachers University, Xinzhou 034000, Shanxi, China

(C) Wuhan University 2021

Abstract: Wooden furniture production consumes a lot of forest resource and other resources, so it is important to estimate its environmental effect. In this research, we collected data in a sofa factory of China and appraised its environment impacts by the ecological footprint (EF) methodology. The results showed that the total EF of the sofa factory was 2316.25 gha/year (gha: global hectare). The average EF of a sofa was 0.18 gha/year. For the total EF of the sofa factory, main contribution came from wooden materials (55\%), followed by non-wooden materials $(41.26 \%)$, and these two categories contributed above $96 \%$ of the total EF. Human labor accounted for $2.21 \%$ of the total footprint. The built land and water contributed a little to the total EF. For the total EF of the wooden materials, main contribution came from wood beams $(57.6 \%)$, followed by plywood (41.08\%); and for the total EF of the non-wooden materials, main contribution came from sponge $(95.37 \%)$. In the end, we concluded that the incorporate of recycled wooden material and reused sponge in the sofa production could be viewed as an important strategy to achieve more sustainable manufacturing.

Key words: case study; ecological footprint (EF); the percent contribution; sofa factory

CLC number: X24

\footnotetext{
Received date: 2021-06-20

Foundation item: Supported by the Fundamental Research Funds for the Central Non-profit Research Institution of CAF (CAFYBB2019MB002), and State Forestry Administration of the People's Republic of China (2015-R04) Biography: LI Jianquan, male, Professor, Ph. D., research direction: forest product market and trade, forestry policy and world forestry hot issues. E-mail: jqli2002@163.com

† To whom correspondence should be addressed. E-mail: tougaoyouxiang284@163.com
}

\section{Introduction}

The notion of ecological footprint (EF) was introduced in 1996 by Rees and Wackernagel which was defined as the area of land hypothetically required to provide the resources and to absorb the waste generated by a human population ${ }^{[1]}$. EF was an effective tool to investigate environmental awareness ${ }^{[2]}$, environmental quality ${ }^{[3]}$, effect of the COVID-19 pandemic on society ${ }^{[4]}$ and so on. Recently, EF has been also applied to enterprises which are also considered as the organizations that require goods, services and generate waste ${ }^{[5]}$.

EF can be used to measure the occupation of ecological resources by enterprises, which is helpful to understand the environmental cost of the enterprises. An appropriate definition of the EF for the corporate level is that it determines the space required to support an activity by means of the area needed to provide the resources consumed and to absorb the wastes generate $\mathrm{d}^{[1,6,7]}$. It is estimated by converting all the material consumption and waste generated data of enterprises into the corresponding ecologically productive land area. The ecologically productive land area can be divided into six categories: energy land, degraded or built land, gardens, crop land, forests and sea space ${ }^{[8]}$. Based on the basic principles of the EF, we can establish the accounting model for the EF calculation of an enterprise, which can quantitatively reveal the ecological needs of enterprises.

Although EF has been applied to analyze the environment impacts of production processes for some products, such as nectarine production ${ }^{[9]}$, mobile phones ${ }^{[10]}$, 
textile sector ${ }^{[11]}$, footwear ${ }^{[12]}$, ceramic bricks production $^{[13]}$, drinking water bottles ${ }^{[14]}$, water supply ${ }^{[15]}$, apple production $^{[16]}$, production of wine ${ }^{[17]}$, jackets manufacture ${ }^{[7]}$, and a particleboard manufacturing process ${ }^{[18]}$, there were no previous works regarding the application of the EF methodology to wooden furniture production in peer-reviewed scientific literature although it has important roles in resource utilization and forest conser vation.

In this study, we calculated the EF of a sofa factory to estimate its environmental impacts. The study will provide instructions for creating green factories and developing ecological economy, and provide scientific basis for enterprises to reduce emissions and achieve carbon neutrality.

\section{Materials and Methods}

\subsection{Description of the Manufacturing Process}

The sofa manufacturing process was investigated in a factory in China and shown in Fig. 1. The first step is to prepare wood and wood-based panels and to select the materials from them according to the different types, and then machine the selected materials into sofa framework; at the same time, prepare the fabrics for sofa, and then loft them, clip and sew the fabrics into the suitable sofa cover. The second step is to spread out both framework and cover, match and stitch them into the final products, inspect the final products and package them, and finally put them in storage area.

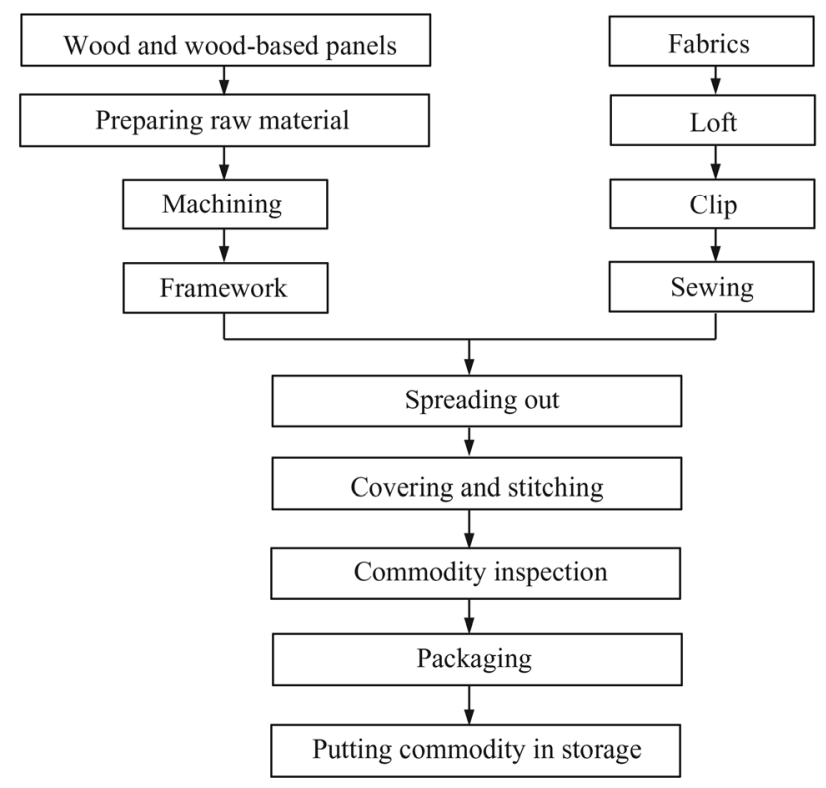

Fig. 1 Diagram of the sofa manufacturing process

\subsection{EF}

The EF of sofa production was obtained by summing up the EF of all the material consumed and waste generated during the production process based on the methods of Kitzes and Wackernagel ${ }^{[19]}$. In the calculation, equivalence factors are used to transform the results expressed into global hectare (gha) over hectares $\left(\mathrm{hm}^{2}\right)$. The equivalence factors are shown in Table $1^{[20]}$. The data used in this study were grouped into the following categories: human labor, built land, water, machinery, wooden raw material (wood beam, medium density fiberboard, plywood), non-wooden raw materials (adhesive, cotton fabric, leather, steel, iron, sponge, imitation leather, microfiber, slider and packaging materials), and electricity. The raw material consumption value in the process of sofa production was obtained from the data of the invested factory in 2015.

Table 1 Equivalence factors of different kinds of productive

\begin{tabular}{cc}
\multicolumn{2}{c}{ land } \\
\hline gha $\cdot \mathrm{hm}^{-2}$ \\
\hline Productive land category & Equivalence factor \\
\hline Cropland & 2.51 \\
Pastures & 0.46 \\
Forest & 1.26 \\
Productive sea & 0.37 \\
Built land & 2.51 \\
\hline
\end{tabular}

\subsubsection{Determination of the EF of human labor}

The value of the average EF per capita in China is used as a proxy for the average EF per employee in this sofa factory. The EF of all the employees working in product related activities is then calculated by multiplying by the number of employees and then adjusted by working hours per year ${ }^{[9,16]}$.

\subsubsection{Determination of the EF of built land \\ $\mathrm{EF}$ of built land is determined by}

$$
\mathrm{EF}_{\mathrm{wb}}=S \times \mathrm{ef}_{\mathrm{b}}
$$

where $\mathrm{EF}_{\mathrm{wb}}\left(\mathrm{gha} \cdot \mathrm{year}^{-1}\right)$ is weighted $\mathrm{EF}$ of built land, $S$ $\left(\mathrm{hm}^{2} \cdot \mathrm{year}^{-1}\right)$ is surface area consumed, $\mathrm{ef}_{\mathrm{b}}\left(\mathrm{gha} \cdot \mathrm{hm}^{-2}\right)$ is equivalence factor of built land.

The land used directly is considered to have the productivity of agricultural land, since most of the infrastructure and built environment are located in areas of agricultural quality ${ }^{[21]}$.

\subsubsection{Determination of the EF of water consumption}

The forest is considered as a water producer, whereby the consumption of this resource is included in that of forest land. In order to calculate forest productiv- 
ity, the hypothesis that a forest of wetlands can produce $1500 \mathrm{~m}^{3}$ of fresh water per hectare per year is assumed $^{[21]}$. Therefore, the formula employed for the calculation of the $\mathrm{EF}$ of water consumption is:

$$
\mathrm{EF}_{\mathrm{ww}}=\frac{W}{\mathrm{FP}} \times \mathrm{ef}_{\mathrm{f}}
$$

where $\mathrm{EF}_{\mathrm{ww}}\left(\mathrm{gha} \cdot \mathrm{year}^{-1}\right.$ ) is weighted ecological footprint of water consumption, $W\left(\mathrm{~m}^{3}\right)$ is water consumption, $\mathrm{FP}\left(\mathrm{m}^{3} \cdot \mathrm{hm}^{-2} \cdot \mathrm{year}^{-1}\right)$ is forest productivity, and $\mathrm{ef}_{\mathrm{f}}$ (gha $\cdot \mathrm{hm}^{-2}$ ) is equivalence factor of forests.

1.2.4 Determination of the EF of machinery

Machinery plays an important role in sofa production. It affects the quality of product, the speed of production, and the degree of environmental pollution. The EF of machinery should not be ignored.

$$
\begin{aligned}
k & =\frac{U}{\mathrm{GNP}} \\
U & =R+N+I-O
\end{aligned}
$$

where $k$ (sej/CNY, sej: solar emjoule) is emergy/money ratio, $U$ (sej) is total used emergy, $R$ (sej) is renewable emergy, $N$ (sej) is non-renewable emergy $I$ (sej) is input emergy, $O$ (sej) is output emergy, and GNP(CNY) is Gross National Product in China ${ }^{[22-29]}$.

$$
\mathrm{EF}_{\mathrm{m}}=\frac{p \times k}{y \times d} \times \mathrm{ef}_{\mathrm{f}}
$$

where $\mathrm{EF}_{\mathrm{m}}$ (gha year $^{-1}$ ) is the $\mathrm{EF}$ of machine, $p(\mathrm{CNY})$ is the price of machine, $y$ (year) is the working years of machine, and $d\left(\mathrm{sej} \cdot \mathrm{hm}^{-2}\right)$ is global average energy density.

The ecological footprint of machinery is allocated to $\mathrm{CO}_{2}$ absorption land.

\subsubsection{Determination of the EF of wooden raw materials}

Wooden raw materials are used for supporting parts of sofa. In the factory, wooden raw materials of sofa include wood beam, medium density fiberboard and plywood. The total wood consumption value and the EF of wooden raw materials are determined by

$$
V=\sum_{i} T_{i} \times v_{i}
$$

where $V\left(\mathrm{~m}^{3}\right)$ is the total wood consumption value, $T_{i}$ is wood conversion coefficient of raw material $i$ (Table 2), and $v_{i}\left(\mathrm{~m}^{3}\right)$ is the consumption value of wooden raw material $i$.

$$
\mathrm{EF}_{\mathrm{wm}}=\frac{V}{\mathrm{NP}} \times \mathrm{ef}_{\mathrm{f}}
$$

where $\mathrm{EF}_{\mathrm{wm}}$ is the $\mathrm{EF}$ of wooden raw materials, and $\mathrm{NP}$ is the natural productivity of wood.
Table 2 Wood conversion coefficient of raw material

\begin{tabular}{ccl}
\hline Material & $\begin{array}{c}\text { Conversion } \\
\text { coefficient }\end{array}$ & Source \\
\hline Wood beam & 1.46 & Ref. [30] \\
Medium density fiberboard & 2.0 & Ref. [31] \\
Plywood & 2.3 & Ref. [31] \\
\hline
\end{tabular}

The ecological footprint of the wooden raw material is allocated to forest.

\subsubsection{Determination of the EF of electricity}

In China, $78 \%, 2 \%$ and $20 \%$ of electricity was generated from fossil fuels (mainly from coal), nuclear and renewable sources, respectively ${ }^{[29]}$. It is assumed that renewable energies have very high energy productivity $(E P)^{[1]}$. The construction of wind parks and hydraulic plants has minimal emission and their energy footprint is considered irrelevant compared with the energy footprint from fossil fuels and nuclear energy.

The ecological footprint of electricity is determined using the following expression

$$
\mathrm{EF}_{\mathrm{we}}=\sum_{j} \frac{P_{j}}{\mathrm{EP}_{j}} \times \mathrm{ef}_{\mathrm{f}}
$$

where $\mathrm{EF}_{\text {we }}\left(\right.$ gha $\cdot$ year $\left.^{-2}\right)$ is weighted ecological footprint of electricity consumption, $P_{j}(\mathrm{~J})$ is primary energy consumption of source $j$, and $\mathrm{EP}_{j}\left(\mathrm{~J} \cdot \mathrm{hm}^{-2} \cdot\right.$ year $\left.^{-1}\right)$ is energy productivity of source $j$.

The EP and the efficiency factor for electricity production of various energy sources are shown in Table $3^{[21,32]}$.

Table 3 EP and the efficiency factor of various energy sources

\begin{tabular}{ccc}
\hline Energy source & $\mathrm{EP} / 10^{9} \mathrm{~J} \cdot \mathrm{hm}^{-2} \cdot \mathrm{year}^{-1}$ & Efficiency factor \\
\hline Oil & 71 & - \\
Coal & 55 & 0.30 \\
Nuclear & 71 & 0.30 \\
\hline
\end{tabular}

The ecological footprint of electricity is allocated to $\mathrm{CO}_{2}$ absorption land.

1.2.7 Determination of the EF of non-wooden raw materials

Non-wooden raw materials for sofa production include adhesive, cotton fabric, leather, steel, iron, sponge, imitation leather, microfiber, slider and packaging materials.

In the factory, imitation leather and microfiber were made of synthetic fabric. Slider belonged to metal accessories. All packaging materials were made of plastic. 
The EF of non-wooden materials as well as the EF of packaging materials is determined using the following expression

$$
\mathrm{EF}_{\mathrm{nwm}}=\sum \frac{C_{\mathrm{m} i} \times E_{\mathrm{semi} i}}{\mathrm{EP}} \times \mathrm{ef}_{\mathrm{f}}
$$

where $\mathrm{EF}_{\text {nwm }}\left(\right.$ gha $\cdot$ year $^{-1}$ ) is the weighted $\mathrm{EF}$ of nonwooden materials or packaging materials, $C_{\mathrm{m} i}(\mathrm{~kg})$ is the consumption of material $i, E_{\mathrm{sem} i}\left(\mathrm{~J} \cdot \mathrm{kg}^{-1}\right)$ is the specific embodied energy of material $i$ (Table 4) and EP $\left(\mathrm{J} \cdot \mathrm{hm}^{-2} \cdot\right.$ year $\left.^{-1}\right)$ is the energy productivity (oil).

Table 4 Embodied energy of material

\begin{tabular}{ccc}
\hline Material & $\begin{array}{c}\text { Embodied energy of } \\
\text { material } / 10^{6} \cdot \mathrm{J}^{-2} \mathrm{~kg}^{-2}\end{array}$ & Source \\
\hline Adhesive & $3.1 \times 10^{-3}$ & Ref. [18] \\
Cotton fabric & 10 & Ref. [5] \\
Leather & 75.8 & Ref. [33] \\
Steel & 36.56 & Ref. [17] \\
Iron & 36.03 & Ref. [17] \\
Synthetic fabric & 43.75 & Ref. [5] \\
Metal accessories & 100 & Ref. [5] \\
Plastic & 43.75 & Ref. [5] \\
\hline
\end{tabular}

The EF of sponge is calculated in the method described in Section 1.2.4 due to the absence of energy intensity.

The ecological footprint of the non-wooden materials is allocated to $\mathrm{CO}_{2}$ absorption land.

\section{Results}

\subsection{Total and Componential EF of the Sofa Factory}

In total, we estimated the EF of the sofa factory was 2306.25 gha year $^{-1}$ by summing up all the consumption for producing sofa. The average EF of a sofa produced was 0.18 gha year $^{-1}$. Concretely, the EF of the human labor was 51.3 gha year ${ }^{-1}$ based on the EF per capita of 2.2 gha year $^{-1}$ in China ${ }^{[34]}$. The EF of the built land was 2.69 gha year ${ }^{-1}$ based on the area of $1.07 \mathrm{hm}^{2}$ and an equivalence factor of $2.51 \mathrm{gha} / \mathrm{hm}^{2}$. The EF of the water consumption in the factory was 0.29 gha year ${ }^{-1}$ based on water consumption of $350 \mathrm{~m}^{3} \cdot \mathrm{year}^{-1}$. The EF of the machinery was 21.49 gha year $^{-1}$. The EF of the wooden raw material yielded a figure of $1274.05 \mathrm{gha} \cdot \mathrm{year}^{-1}$ based on the natural productivity of wood in the world of $1.29 \mathrm{~m}^{3} \cdot \mathrm{hm}^{-2}$ according to the research of $\mathrm{Li}$ et $a l^{[35]}$, The $\mathrm{EF}$ of the non-wooden raw materials reached to $955.51 \mathrm{gha} \mathrm{year}^{-1}$. The EF of electricity was 10.92 gha year $^{-1}$ (Fig. 2).

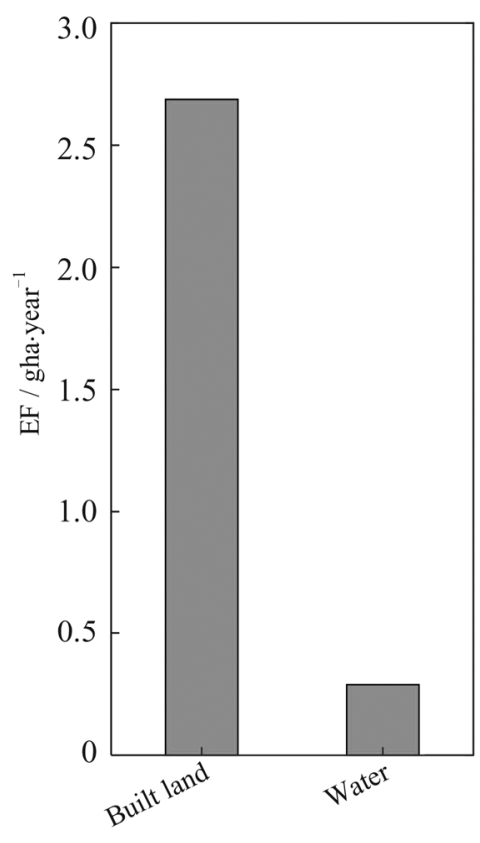

(a) Small EF

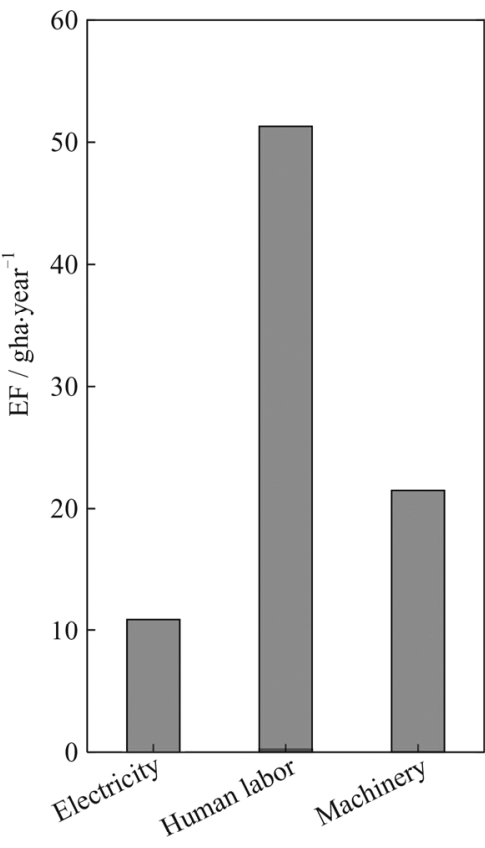

(b) Medium EF

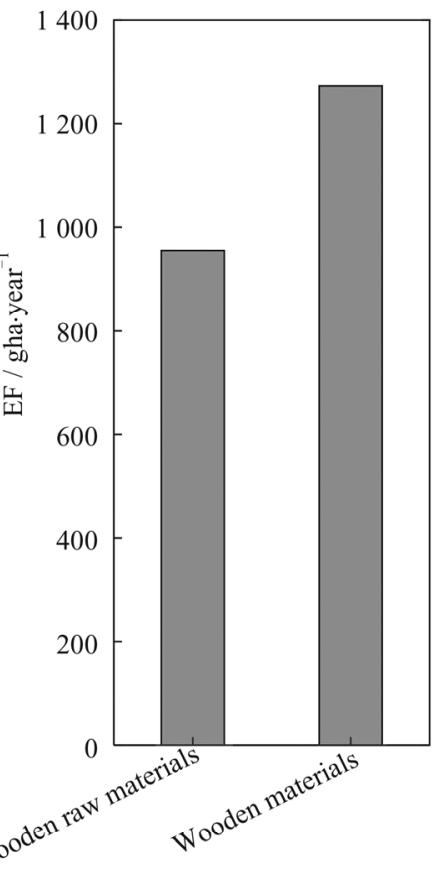

(c) Large EF

Fig. 2 The componential EF of the sofa factory 


\subsection{Total and Componential EF of Wooden Raw Materials for Producing Sofa}

Wooden raw materials for sofa production include wood beam, medium density fiberboard and plywood. The total EF of wooden raw materials was 1274.0 gha year $^{-1}$ by summing up all the componential EFs. The EF of wood beam, medium density fiberboard and plywood was $733.85,16.86$ and 523.35 gha year ${ }^{-1}$, respectively (Fig. 3).

\subsection{Total and Componential EF of Non-Wooden Raw Materials for Producing Sofa}

Non-wooden raw materials for sofa production include adhesive, cotton fabric, leather, steel, iron, sponge, imitation leather, microfiber, slider as well as packaging materials. The EF of adhesive, cotton fabric, leather, steel, iron, imitation leather, microfiber and slider were calculated in the method described in Section 1.2.6. The $\mathrm{EF}$ of sponge was calculated in the method described in Section 1.2.4 due to the absence of its energy intensity.

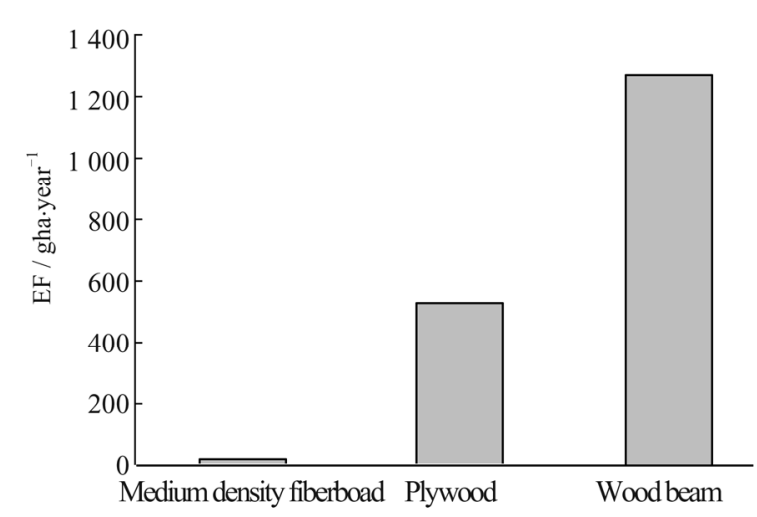

Fig. 3 The componential EF of the wooden raw materials

The total EF of non-wooden raw materials was 955.51 gha year $^{-1}$ by summing up all the componential EFs. The $\mathrm{EF}$ values of adhesive, iron, microfiber, slider, steel, cotton fabric, imitation leather, leather, packaging materials and sponge were $0.0003,0.93,0.29,0.64,0.51,20.99,4.76$, $3.56,12.36$ and 911.47 gha year $^{-1}$, respectively (Fig. 4).

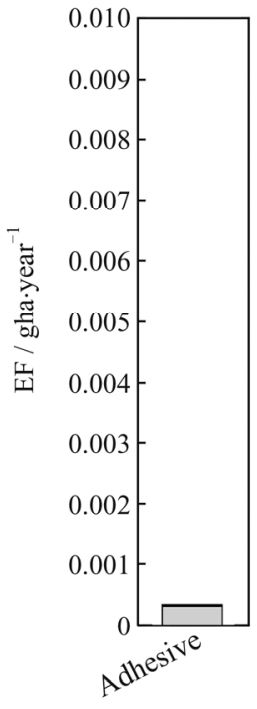

(a) Subtle EF

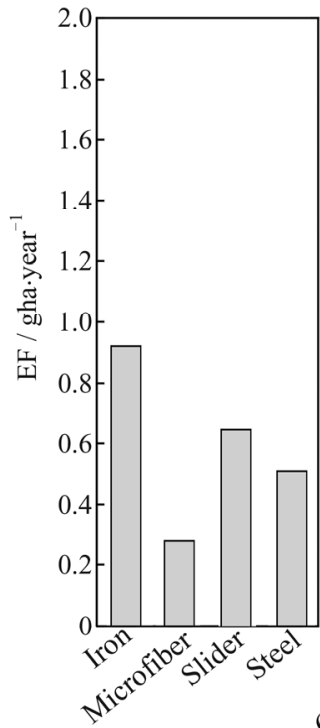

(b) Small EF

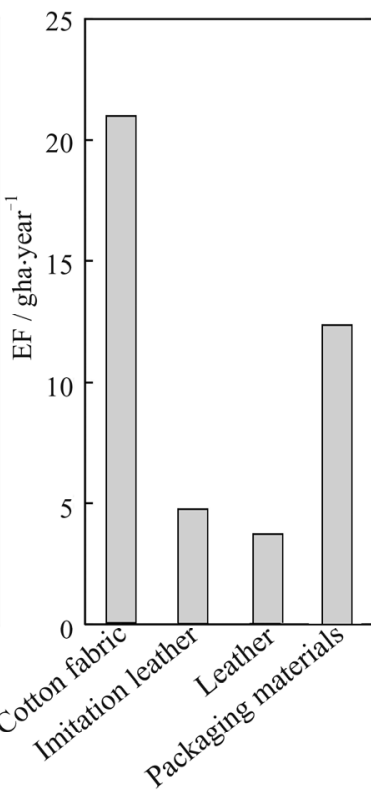

(c) Medium EF

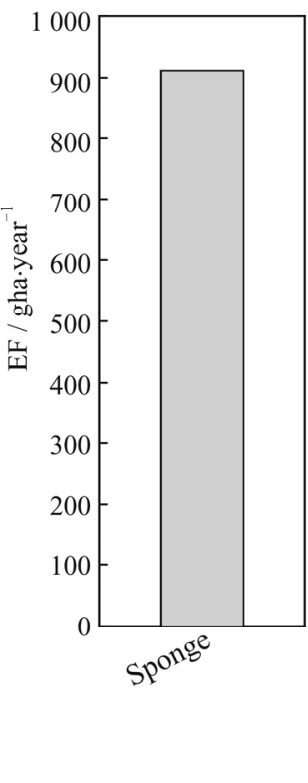

(d) Large EF

Fig. 4 The componential EF of the non-wooden raw materials

\subsection{Contributions of Different Components to the Total EF of the Sofa Production}

Figure 5 shows the contributions of different components to the total $\mathrm{EF}$ of sofa production. In the total $\mathrm{EF}$ of the sofa production, the main contribution came from wooden materials $(55 \%)$, followed by non-wooden materials $(41.26 \%)$, and these two categories contributed above $96 \%$ of the total EF. Human labor accounted for $2.21 \%$ of the total footprint. The built land and water contributed a little to the total $\mathrm{EF}$, the former accounted for $0.12 \%$, and the later for only $0.01 \%$.

In the total $\mathrm{EF}$ of the wooden raw materials, the main contribution came from wood beam $(57.6 \%)$, followed by plywood $(41.08 \%)$, and these two categories contributed above $98 \%$ of the total EF. Medium density fiberboard only accounted for $1.32 \%$ of the total footprint.

In the total EF of the non-wooden raw materials, the 
main contribution came from sponge (above 95\%). Cotton fabric accounted for $2.21 \%$ of the total footprint.

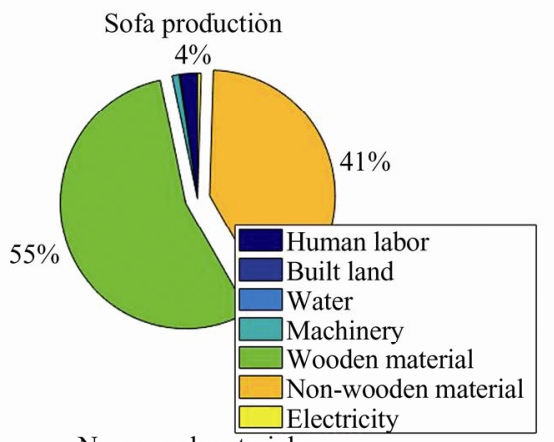

Non-wood materials

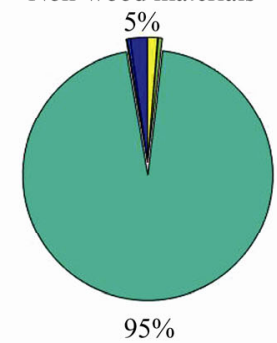

Packaging materials accounted for $1.28 \%$ of the total footprint.

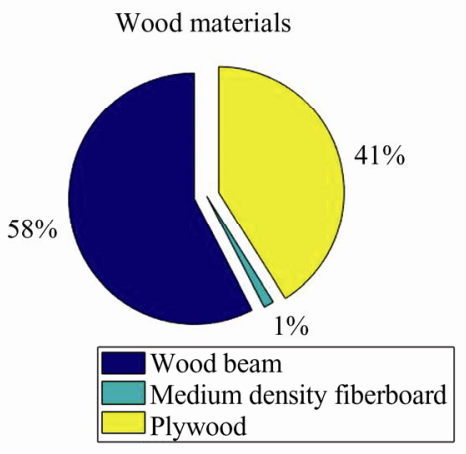

Fig. 5 Percent contributions of different components to the total EF of sofa production

\section{Discussions}

\subsection{EF as a Powerful Tool for Manufacturers}

Sustainability in the manufacturing sector is essential in the process of sustainable development for the whole society ${ }^{[36]}$. Sustainable manufacturing is defined as "the creation of manufactured products that use processes that are non-polluting, conserve energy and natural resources, and are economically sound and safe for employees, communities, and consumers" ${ }^{,[37]}$. Gaussin et $a l^{[36]}$ and Joshi et $a l^{[38]}$ emphasized the importance of reduce, reuse and recycle in the process of improving sustainability in the product manufacturing process. $\mathrm{EF}$ could help manufacturers analyze the productive processes and decrease environmental impacts. In our study, the total EF of the sofa factory was mainly influenced by the raw material, especially by the wooden material and sponge due to their high requirements. Therefore, strategies to reduce the EF for this sofa factory could focus on using recycled wooden material and reused sponge.

Although EF is an effective approach to measure the environmental impacts of products, its application to product is sometimes impeded due to the absence of data. Fortunately, science and technology development helps us solve this problem. The sofa factory we investigated adopts Enterprise Resource Planning (ERP) information management system in its logistics management. By using ERP, each kind of goods has its own unique bar code. Staff members can get the information of the goods by scanning bar code, which allows us to get all data in the sofa production process accurately and efficiently. Therefore, our results were relatively reliable and the method we used also can be used for other related studies.

\subsection{EF as a Powerful Tool for Consumers}

The product EF is a measure of ecoefficiency as it expresses the ecological impact per unit of product ${ }^{[16]}$. In our study, the sofa EF was 0.18 gha per item. In the same way, Saravia-Cortez et al ${ }^{[18]}$ showed the particleboard EF ranged from 0.896 to $0.020 \mathrm{gha} / \mathrm{m}^{3}$ corresponding to the ratio of recycled wood wastes employed ranged from 0 to $100 \%$. Cerutti et al ${ }^{[9]}$ calculated the total footprint was $1.34 \mathrm{gha} / \mathrm{t}$ nectarines produced in an orchard in Piedmont (Italy). Cerutti et $a l^{[39]}$ reported that the $\mathrm{EF}$ was 0.93 gha/t in nectarine production systems and was $8.04 \mathrm{gha} / \mathrm{t}$ in hazelnut production systems. The EF can be used to compare the ecological impact of the same products and different products. Therefore, if the EF value can be shown on the side of the packaging as an eco-label, consumers would conduct comparisons and express their ecological preferences.

At the present, limited information directly related 
to environmental impacts of products is available to the consumers despite their rising consumer environmental awareness. We suggest the EF methodology should be applied to a wider range of products in order to make it as a practical market tool to guide the consumers for choosing environment-friendly products.

\section{Conclusion}

We successfully assessed the environmental impacts of the sofa factory in China by applying the EF method. The EF of the sofa factory was 2316.25 gha/year, of which $1274.0 \mathrm{gha} /$ year was from the wooden material and $911.47 \mathrm{gha} /$ year was from sponge. These two components yielded the most significant impact on the total EF. Therefore, the incorporate of recycled wooden material and reused sponge in the sofa production could be viewed as an important strategy to achieve more sustainable manufacturing.

\section{Acknowledgement}

The authors gratefully thank the manager and field technicians of the sofa factory for their collaboration. An acknowledgment also goes to China National Furniture Association (CNFA) for its excellent work in coordination.

\section{References}

[1] Wackernagel M, Rees W. Our Ecological Footprint: Reducing Human Impact on the Earth [M]. Philadelphia: New Society Publishers, 1996.

[2] Simsar A. Young children's ecological footprint awareness and environmental attitudes in Turkey [J]. Child Indicators Research, 2021, 14(4): 1387-1413.

[3] Koyuncu T, Beser M K, Alola A A. Environmental sustainability statement of economic regimes with energy intensity and urbanization in Turkey: A threshold regression approach [J]. Environmental Science and Pollution Research, 2021, 28(31): 42533-42546.

[4] Echegaray F. What POST-COVID-19 lifestyles may look like? Identifying scenarios and their implications for sustainability [J]. Sustainable Production and Consumption, 2021, 27: 567-574.

[5] Butnariu A, Avasilcai S. Research on the possibility to apply ecological footprint as environmental performance indicator for the textile industry [J]. Procedia-Social and Behavioral Sciences, 2014, 124: 344-350.

[6] Monfreda C, Wackernagel M, Deumling D. Establishing national natural capital accounts based on detailed ecological footprint and biological capacity assessments [J]. Land Use Policy, 2004, 21: 231-246.

[7] Herva M, Álvarez A, Roca E. Combined application of energy and material flow analysis and ecological footprint for the environmental evaluation of a tailoring factory [J]. Journal of Hazardous Materials, 2012, 237-238: 231-239.

[8] Bicknell K B, Ball R J, Cullen R, et al. New methodology for the ecological footprint with an application to the New Zealand economy [J]. Ecological Economics, 1998, 27(2): 149160.

[9] Cerutti A K, Bagliani M, Beccaro G L, et al. Application of ecological footprint analysis on nectarine production: Methodological issues and results from a case study in Italy [J]. Journal of Cleaner Production, 2010, 18: 771-776.

[10] Frey S D, Harrison D J, Billett E H. Ecological footprint analysis applied to mobile phones [J]. Journal of Industrial Ecology, 2006, 10(1-2): 199-216.

[11] Herva M, Franco A, Ferreiro S, et al. An approach for the application of the ecological footprint as environmental indicator in the textile sector [J]. Journal of Hazardous Materials, 2008, 156(1): 478-487.

[12] Herva M, Álvarez A, Roca E. Sustainable and safe design of footwear integrating ecological footprint and risk criteria [J]. Journal of Hazardous Materials, 2011, 192: 1876-1881.

[13] Herva M, García-Diéguez C, Franco-Uría A, et al. New insights on ecological footprinting as environmental indicator for production processes [J]. Ecological Indicators, 2012, 16: 84-90.

[14] Herva M, Franco-Uría A, Carrasco E F, et al. Application of fuzzy logic for the integration of environmental criteria in eco-design [J]. Expert Systems with Applications, 2012, 39: 4427-4431.

[15] Lenzen M, Lundie S, Bransgrove G, et al. Assessing the ecological footprint of a large metropolitan water supplier: Lessons for water management and planning towards sustainability [J]. Journal of Environmental Planning and Management, 2003, 46 (1): 113-141.

[16] Limnios E A M, Ghadouani A, Schilizzi S G M, et al. Giving the consumer the choice: A methodology for product ecological footprint calculation [J]. Ecological Economics, 2009, 68: $2525-2534$.

[17] Niccolucci V, Galli A, Kitzes J, et al. Ecological footprint analysis applied to the production of two Italian wines [J]. Agriculture Ecosystems and Environment, 2008, 128(3): 162-166.

[18] Saravia-Cortez A M, Herva M, García-Diéguez C, et al. Assessing environmental sustainability of particleboard production process by ecological footprint [J]. Journal of 
Cleaner Production, 2013, 52: 301-308.

[19] Kitzes J, Wackernagel M. Answers to common questions in ecological footprint accounting [J]. Ecological Indicators, 2009, 9(4): 812-817.

[20] World Wide Fund for Nature. Living Planet Report 2010 [EB/OL]. [2021-06-16] http://assets.panda.org/downloads/ lpr2010.pdf.

[21] Solís-Guzmán J, Marrero M, Ramírez-de-Arellano A. Methodology for determining the ecological footprint of the construction of residential buildings in Andalusia (Spain) $[\mathrm{J}]$. Ecological Indicators, 2013, 25: 239-249.

[22] Lan S F, Qin P, Lu S F. Ecological Economic System Emergy Analysis [M]. Beijing: Chemical Industry Press, 2002(Ch).

[23] Department of Energy Statistics, National Bureau of Statistics. China Energy Statistical Yearbook [M]. Beijing: China Statistics Press, 1989(Ch).

[24] Department of Energy Statistics, National Bureau of Statistics. China Energy Statistical Yearbook [M]. Beijing: China Statistics Press, 1996(Ch).

[25] Department of Energy Statistics, National Bureau of Statistics. China Energy Statistical Yearbook [M]. Beijing: China Statistics Press, 2014(Ch).

[26] National Bureau of Statistics of China. China Statistical Yearbook [M]. Beijing: China Statistics Press, 1984(Ch).

[27] National Bureau of Statistics of China. China Statistical Yearbook [M]. Beijing: China Statistics Press, 2001(Ch).

[28] National Bureau of Statistics of China. China Statistical Yearbook [M]. Beijing: China Statistics Press, 2004(Ch).

[29] National Bureau of Statistics of China. China Statistical Yearbook [M]. Beijing: China Statistics Press, 2015(Ch).

[30] Zhu Z M. Sawmilling and Lumber Inspection Technology [M]. Beijing: China Forestry Press, 2007: 116-120.

[31] Yin Z H, Tian M H. Analysis of gains or losses of chinese timber imports in great quantities [J]. Forestry Economics, 2006(9): 47-50(Ch).

[32] González-Vallejo P, Marrero M, Solís-Guzmán J. The ecological footprint of dwelling construction in Spain [J]. Ecological Indicators, 2015, 52: 75-84.

[33] Xia H P. Measurement and Analysis of the Ecological Footprint in the Chinese International Trade [D]. Hangzhou: Zhejiang University, 2012(Ch).

[34] Xie G D, Cao S Y, Yang Q S, et al. Living Planet Report China 2015 [EB/OL]. [2021-05-14]. http://www.docin.com/ p-1535085428. html.

[35] Li J Q, Tian K, Chen S Z. Change of Beijing's ecological footprint and its countermeasure in the New Century [J]. Forestry Economics, 2013 (4): 102-109(Ch).

[36] Gaussin M, Hu G, Abolghasem S, et al. Assessing the environmental footprint of manufactured products: A survey of current literature [J]. International Journal of Production Economics, 2013, 146(2): 515-523.

[37] Westkämper E, Alting L, Arndt G. Life cycle management and assessment: Approaches and visions towards sustainable manufacturing [J]. CIRP Annals, 2000, 49(2): 501-526.

[38] Joshi K, Venkatachalam A, Jawahir I S. A new methodology for transforming $3 \mathrm{R}$ concept into $6 \mathrm{R}$ concept for improved product sustainability [C]// IV Global Conference on Sustainable Product Development and Life Cycle Engineering. 2006: 3-6.

[39] Cerutti A K, Beccaro G L, Bagliani M, et al. Multifunctional ecological footprint analysis for assessing eco-efficiency: A case study of fruit production systems in Northern Italy [J]. Journal of Cleaner Production, 2013, 40: 108-117. 